\title{
Análise da Arborização de Quatro Praças no Bairro da Tijuca, RJ, Brasil
}

\author{
Welington Kiffer de Freitas ${ }^{1}$, Marco Aurélio Soares Pinheiro², \\ Leandro Luiz Ferreira Abrahão ${ }^{3}$
}

\author{
${ }^{1}$ Escola de Engenharia Industrial e Metalúrgica - EEIMVR, Universidade Federal Fluminense - UFF, \\ Volta Redonda/RJ, Brasil \\ ${ }^{2}$ Secretaria de Educação do Estado do Rio de Janeiro - SEEDUC, Rio de Janeiro/RJ, Brasil \\ ${ }^{3}$ Universidade Federal Rural do Rio de Janeiro - UFRRJ, Seropédica/RJ, Brasil
}

\begin{abstract}
RESUMO
Neste estudo foi realizada a avaliação da arborização de quatro praças da Tijuca, Rio de Janeiro, RJ, considerando a riqueza de espécies, análises morfométricas dos indivíduos, além do seu diagnóstico fitossanitário. Foram encontradas 310 árvores, distribuídas em 36 espécies e 14 famílias, com destaque para Cassia siamea e Delonix regia que, juntas, corresponderam a 32,4\% dos indivíduos. Cassia siamea representou 9,4\% dos indivíduos da Praça Castilho França, 32,3\% da Varnhagen, 24,0\% da Saens Pena e 11,1\% da Xavier de Brito. Já Delonix regia totalizou 3,2\% das espécies da Praça Varnhagen, 10,7\% da Saens Pena e 35,2\% da Xavier de Brito. Nas quatro praças foi encontrada uma distribuição proporcional entre as espécies exóticas e nativas. Todavia, comparando o número de indivíduos, foi constatado predomínio das exóticas. Considerando todos os indivíduos amostrados, 83,6\% concentraram-se entre $5 \mathrm{~m}$ e $15 \mathrm{~m}$ de altura. Observou-se que 49,5\% das árvores apresentaram DAP maiores que $30 \mathrm{~cm}$. Considerando-se os aspectos fitossanitários, $64,5 \%$ das árvores encontravam-se saudáveis e 25,4\% mostravam sinais de ataques de pragas, além disso, 10,1\% sofreram injúrias. Diante desses fatos, recomenda-se a substituição dos indivíduos debilitados que sejam uma ameaça aos usuários ou prejudiquem a estética, procurando sempre utilizar o maior número de espécies nativas possível, para evitar a uniformidade. Também se faz necessário intensificar o controle das pragas e as atividades de educação ambiental, com o intuito de reduzir os danos nos exemplares da flora das praças urbanas.
\end{abstract}

Palavras-chave: florística, espécies arbóreas, diagnóstico de árvores, arborização urbana.

\section{Urban Tree Planting Analysis in Four Squares of Tijuca, Rio de Janeiro, Brazil}

\begin{abstract}
In the present study, we conducted a tree planting evaluation in four squares of Tijuca, Rio de Janeiro, where we analyzed the species richness, diameter at breast height (DBH) and height of subjects, and we also performed a diagnosis of plant health. We found 310 individuals, distributed in 36 species and 14 families, with more emphasis on Cassia siamea and Delonix regia (32.4\%). Cassia siamea represented 9.4\% of the subjects of Castilho France square, $32.3 \%$ of Varnhagen square, $24.0 \%$ of Saens Pena square and $11.1 \%$ of Xavier de Brito square. Delonix regia totaled $3.2 \%$ of the species of Varnhagen square, $10.7 \%$ of Saens Pena and $35.2 \%$ of Xavier de Brito. A proportional distribution between exotic and native species was observed in the four squares investigated; however, a predominance of exotic species was found when the number of subjects was compared. $83.6 \%$ of the subjects presented height between 5 and $15 \mathrm{~m}$. It was possible to
\end{abstract}


observe that $49.5 \%$ of the trees showed DBH greater than $30 \mathrm{~cm} .64 .5 \%$ of the trees are healthy, $25.4 \%$ are being attacked by pests, and $10.1 \%$ have suffered worrying injuries. Given these facts, we recommend the replacement of debilitated subjects that represent a threat to users or impair aesthetics, always trying to use the largest possible number of native species to avoid uniformity. It is also necessary to intensify the control of pests and environmental education activities in order to reduce damage to flora specimens of urban squares.

Keywords: floristics, tree species, diagnosis of tree, urban tree.

\section{INTRODUÇÃO}

A praça como espaço público sempre teve um referencial urbano marcado pela convivência humana, servindo como um importante equipamento históricocultural urbano que, especialmente no Brasil, expressa o surgimento e desenvolvimento de inúmeras cidades (Romani et al., 2012).

No contexto atual, as praças são definidas como espaços livres públicos, com forte função social, inseridas na malha urbana como elementos organizadores da circulação e de amenização pública, geralmente contendo expressiva cobertura vegetal, mobiliário lúdico, canteiros e bancos (Harder, 2002; Mendonça, 2007; Lindenmaier \& Santos, 2008).

As praças prestam inúmeros serviços ambientais aos centros urbanos, dentre eles pode-se citar a melhoria da qualidade do ar, através da fixação do dióxido de carbono $\left(\mathrm{CO}_{2}\right)$, emitido principalmente pelos veículos automotivos, e liberação de oxigênio $\left(\mathrm{O}_{2}\right)$ através do processo de fotossíntese (Albertin et al., 2011). Conforme Nucci (1996), as praças ainda servem como barreira ou obstáculo para a propagação do som e de resíduos sólidos no ar; atuam na estabilidade climática, com a redução de temperatura e aumento da umidade do ar; favorecem a melhoria das condições do solo urbano, do ciclo hidrológico, facilitando o escoamento e absorção das águas pluviais pelo solo. Albertin et al. (2011) ainda reforçam sua importância quanto aos aspectos paisagísticos (p. ex., mudança de textura do elemento construído e aspectos estéticos); psicológicos (p. ex., conforto e bem-estar que elas reproduzem) e ecológicos (p. ex., fonte de abrigo e alimento para a fauna urbana).

A Sociedade Brasileira de Arborização Urbana (SBAU) propôs como índice mínimo para áreas verdes públicas destinadas à recreação o valor de $15 \mathrm{~m}^{2}$ por habitante, que embora muito baixo não é atingido pela maioria das cidades brasileiras (Harder et al., 2006; Souza et al., 2011).

Dessa forma, o planejamento da arborização urbana e das praças públicas é fundamental para o desenvolvimento urbano, pois sem ele a expansão das cidades pode ocorrer de forma negativa, afetando diretamente a qualidade de vida dos cidadãos (Silva Filho \& Bortoleto, 2005; Kramer \& Krupek, 2012).

Toda cidade deveria investir em programas de estudos sobre o espaço urbano para a elaboração de um plano de arborização que busque valorizar os aspectos paisagísticos e ecológicos, priorizando o uso de espécies nativas com potencialidade para esse tipo de uso (Kramer \& Krupek, 2012).

No planejamento da arborização de praças e logradouros urbanos geralmente nota-se baixa diversidade de espécies utilizadas, apesar da enorme variedade da flora nativa de cada região, como é próprio do clima tropical (Gonçalves \& Paiva, 2004; Silva Filho \& Bortoleto, 2005). Gonçalves \& Paiva (2004) relatam que a baixa diversidade de espécies na arborização urbana resulta da preferência pelo uso de espécies exóticas, tanto de outras regiões do país quanto estrangeiras, o que provavelmente ocorre devido ao pouco conhecimento ecológico silvicultural das espécies nativas e/ou pela opção por espécies tradicionalmente utilizadas na arborização de outros lugares. O predomínio de poucas espécies por unidade de área também promove a homogeneidade florística, que se torna um grande risco para a proliferação de pragas e doenças na vegetação urbana (Souza et al., 2011).

O presente trabalho foi realizado com o objetivo de contribuir para o maior conhecimento da composição florística da vegetação arbórea das principais praças do bairro da Tijuca, Rio de Janeiro, RJ, servindo como base para o manejo dos elementos arbóreos. 


\section{MATERIAL E MÉTODOS}

O estudo foi desenvolvido no bairro da Tijuca, localizada na zona norte da cidade do Rio de Janeiro, RJ. Na Região Administrativa da Tijuca residem cerca de 180 mil pessoas, correspondentes a 2,87\% do total da população do município, com a maior parte dos habitantes acima dos 50 anos (IPP, 2012). O bairro possui uma concentração de $4.269,9$ habitantes por $\mathrm{km}^{2}$ e um elevado Índice de Desenvolvimento Humano (IDH) de 0,92 (IPEA, 2000).

Conforme o mapeamento da cobertura vegetal e do uso das terras do município do Rio de Janeiro, a Tijuca possui uma área de 1.006,6 ha: $60,2 \%$ de áreas urbanizadas; $21,1 \%$ com cobertura florestal; $10,8 \%$ com área de reflorestamento desenvolvido pela prefeitura da cidade; e 7,9\% com outros tipos de usos (SMAC, 2012a).

O bairro ainda conta com a presença do Parque Nacional da Tijuca, que segundo Freitas et al. (2006) constitui-se em um parque urbano importante para a manutenção da diversidade da fauna e da flora, contribuindo, também, para a qualidade de vida da população carioca.

Segundo a SMAC (2012b), o clima da cidade do Rio de Janeiro é do tipo tropical, quente e úmido, com variações locais, devidas às diferenças de altitude, vegetação e proximidade do oceano; a temperatura média anual é de $22^{\circ} \mathrm{C}$, com médias diárias elevadas no verão (de $30^{\circ} \mathrm{C}$ a $32^{\circ} \mathrm{C}$ ); as chuvas variam de 1.200 a $1.800 \mathrm{~mm}$ anuais.

Neste estudo foram consideradas quatro praças principais do bairro da Tijuca: Praça Castilho França (também conhecida como Afonso Pena, 1,16 ha), Varnhagen (0,32 ha), Saens Pena (1,07 ha) e Xavier de Brito (ou Praça dos Cavalinhos, 1,07 ha) (Figura 1).

Segundo Braga \& Flemming (2010), essas praças apresentam características bem distintas umas das outras, desde a sua localização, forma, relação com a vizinhança e função que cada uma exerce dentro do bairro, seja para lazer e descanso (Castilho França e Xavier de Brito, apresentando a última variação no fluxo de pessoas, existindo horários específicos de movimento), seja por importância comercial (Saens Pena) ou posição de destaque em relação a um pólo gastronômico (Varnhagen).

Nessas praças, o método de inventário utilizado foi de caráter qualiquantitativo, do tipo censo, também denominado inventário total. A coleta dos dados foi realizada em formulário específico, durante o mês de fevereiro de 2012.

A avaliação foi feita com base na determinação da espécie arbórea. Para classificação das famílias botânicas foi adotado o sistema APG III (2009) e a grafia dos táxons foi conferida junto aos bancos

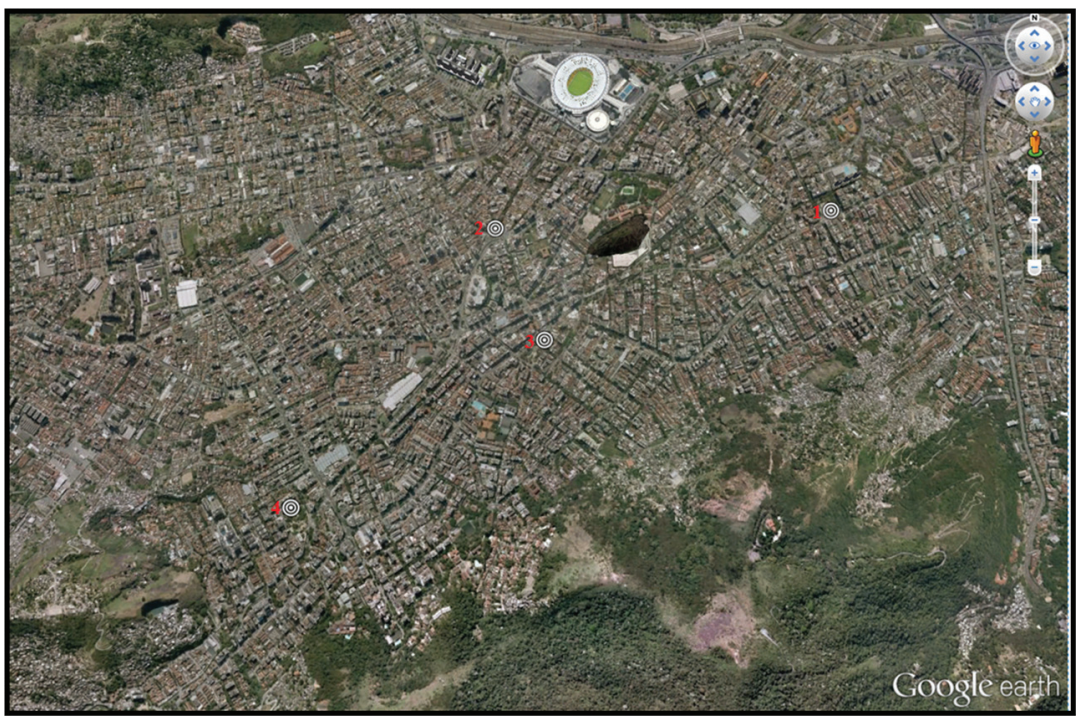

Figura 1. Localização das quatro praças da Tijuca, Rio de Janeiro, RJ. 1 - Castilho de França/2 - Varnhagen/3 Saens Pena/4 - Xavier de Brito.

Figure 1. Location of the four squares of Tijuca, RJ. 1 - Castilho de França/2 - Varnhagen/3 - Saens Pena/4 - Xavier de Brito. 
de dados eletrônicos disponibilizados pelos sites da Flora do Brasil, do Jardim Botânico do Rio de Janeiro (Forzza et al., 2010) e do Missouri Botanical Garden (MOBOT, 2012), sendo cada espécie agrupada conforme sua origem (nativa ou exótica da Mata Atlântica).

Para cada indivíduo foi observado: qualidade da poda, estado fitossanitário, presença ou ausência de área de colo $\left( \pm 1 \mathrm{~m}^{2}\right.$ ) e se apresentava conflitos (aéreo e superficial).

As variáveis dendrométricas consideradas foram: altura $(\mathrm{m})$, diâmetro de copa $\left(\mathrm{m}^{2}\right)$ e circunferência à altura do peito, ou a $1,30 \mathrm{~m}$ do solo, tecnicamente denominado de CAP, mensuradas em centímetros. Multiplicando-se o CAP por $\pi$, obteve-se o Diâmetro à Altura do Peito (DAP). Após o processamento dos dados, as variáveis altura total, DAP e Qualidade de Fuste $(\mathrm{QF})$ foram distribuídas em classes de frequência.

\section{RESULTADOS E DISCUSSÃO}

O censo das espécies nas quatro praças do bairro da Tijuca registrou a presença de um total de 310 indivíduos, distribuídos em 36 espécies, 30 gêneros e 14 famílias botânicas (Tabela 1). Na Praça Castilho França (Afonso Pena) foram observados 96 indivíduos, na Varnhagen, 31, na Saens Pena, 75, e na Xavier de Brito, 108.

A análise quantitativa demonstrou que as famílias botânicas representadas por maior número de espécies foram: Fabaceae, com 13 espécies; Arecaceae, com quatro espécies; e Bignoniaceae, com três espécies (Tabela 1).

Com relação ao número de indivíduos por família, os maiores destaques foram para Fabaceae, com 178 indivíduos (59,3\%), Chrysobalanaceae, com 28 indivíduos (9,3\%), Arecaceae, com 24 indivíduos (8,0\%), Moraceae e Bignoniaceae, com 18 indivíduos cada. A essas espécies pertenciam cerca de $90 \%$ do total de indivíduos encontrados nas quatro praças estudadas. Conforme Lindenmaier \& Santos (2008), a expressiva participação de plantas da família Fabaceae é muito comum na arborização das praças urbanas.

Em estudo realizado por Rocha et al. (2004) no bairro Rancho Novo, em Nova Iguaçu, RJ, também foi possível constatar relativa uniformidade das espécies que compõem a arborização: apenas 20 espécies perfaziam cerca de $90 \%$ da arborização urbana nesse bairro.
Na Praça Castilho França, os maiores destaques, em termos de presença de indivíduos, foram registrados para as espécies Caesalpinia ferrea (26,0\%), Licania tomentosa $(20,8 \%)$ e Caesalpinia echinata (12,5\%). Na Praça Varnhagen, Cassia siamea (32,3\%), Bauhinia variegata $(19,4 \%)$ e Erythrina speciosa (16,1\%) foram as espécies que mais contribuíram em relação ao número de indivíduos. Na Praça Saens Pena foi observado o predomínio de Cassia siamea (24,0\%), Ficus religiosa e Syagrus romanzoffiana ( $16,0 \%$ cada uma). Já na Praça Xavier de Brito as espécies mais ocorrentes foram Delonix regia $(39,2 \%)$ e Cassia siamea $(13,4 \%)$.

A distribuição das espécies mais abundantes não foi regular, como é possível observar na Tabela 1. No total, $32,4 \%$ dos indivíduos identificados pertencem às espécies Cassia siamea (Castilho França - 9,4\%, Varnhagen $32,3 \%$, Saens Pena - 24,0\% e Xavier de Brito - 11,1\%) e Delonix regia (Varnhagen - 3,2\%, Saens Pena - 10,7\% e Xavier de Brito - 35,2\%), o que representa grande concentração desses taxa. Essas espécies pertencem à família Fabaceae, segundo Rocha et al. (2004), não são adequadas para arborização de vias públicas devido à incompatibilidade com locais urbanos. A primeira, em função da fragilidade de seu lenho, que quebra com facilidade, causando transtornos à população; a outra apresenta raiz superficial, que frequentemente emerge e pode danificar calçadas e passeios das praças, com potencial para causar acidentes aos pedestres.

Estudos apontam Cassia siamea e Delonix regia como espécies bastante frequentes na arborização urbana de outras regiões do estado do Rio de Janeiro, como no bairro do Rancho Novo, em Nova Iguaçu, RJ (Souza \& Cintra, 2007), e da Taquara, no Rio, RJ (Rocha et al., 2004).

Redin et al. (2010) recomendam que a frequência de uma única espécie não ultrapasse $15 \%$. Por razões estéticas e fitossanitárias, deve-se estabelecer o número de espécies a utilizar e a proporcionalidade de uso de cada espécie em relação ao total de árvores a serem plantadas. Em todas as praças, as espécies que mais se destacaram atingiram mais de $10 \%$ do valor total dos indivíduos. Conforme Redin et al. (2010), esse fato pode ocasionar riscos relacionados à longevidade por meio de declínio populacional e ataque de pragas ou doenças.

As espécies raras nas praças (aquelas com número de indivíduos variando entre 1 a 7) representaram $69,4 \%$ de 
Tabela 1. Relação das famílias e espécies vegetais arbóreas, com respectivo nome popular, origens, além do número de indivíduos e frequência relativa nas quatro praças selecionadas para este estudo.

Table 1. List of arboreal plant families and species, with their popular names, origins, number of individuals and relative frequency in the four squares selected for this study.

\begin{tabular}{|c|c|c|c|}
\hline $\begin{array}{c}\text { FAMÍLIA } \\
\text { Nome científico }\end{array}$ & Nome popular & Origem & Praças \\
\hline \multicolumn{4}{|l|}{ ANACARDIACEAE } \\
\hline Mangifera indica $\mathrm{L}$. & mangueira & exótica & 1,2 \\
\hline Schinus terebinthifolius Raddi & aroeira & nativa & 2 \\
\hline \multicolumn{4}{|l|}{ ARECACEAE } \\
\hline Chamaerops humilis L. & palma-de-leque & exótica & 1 \\
\hline Cocos nucifera L. & coco & exótica & 1 \\
\hline Roystonea regia (Kunth) O. F. Cook & palmeira-real & exótica & 1,4 \\
\hline Syagrus romanzoffiana (Cham.) Glassman & jerivá & nativa & 2,4 \\
\hline \multicolumn{4}{|l|}{ BIGNONIACEAE } \\
\hline Handroanthus heptaphyllus (Vell.) Mattos & ipê-roxo & nativa & 1,3 \\
\hline Tabebuia rosea (Bertol.) A. DC. & ipê-rosa & nativa & $1,3,4$ \\
\hline Tabebuia sp. & ipê africano & exótica & 1,3 \\
\hline \multicolumn{4}{|l|}{ CHRYSOBALANACEAE } \\
\hline Licania tomentosa (Benth.) Fritsch & oiti & nativa & $1,3,4$ \\
\hline \multicolumn{4}{|l|}{ EUPHORBIACEAE } \\
\hline Alchornea triplinervia (Spreng.) Müll. Arg. & tapiá & nativa & 4 \\
\hline \multicolumn{4}{|l|}{ FABACEAE } \\
\hline Caesalpinia echinata Lam. & pau-brasil & nativa & $1,3,4$ \\
\hline Caesalpinia ferrea Mart. & pau-ferro & nativa & $1,3,4$ \\
\hline Caesalpinia peltophoroides Benth. & sibipiruna & nativa & $1,2,3,4$ \\
\hline Tamarindus indica L. & tamarindo & exótica & 1 \\
\hline Bauhinia variegata $\mathrm{L}$. & pata-de-vaca & exótica & $2,3,4$ \\
\hline Caesalpinia pulcherrima (L.) Sw. & barba-de-barata & nativa & 1 \\
\hline Cassia fistula L. & chuva-de-ouro & exótica & 1,4 \\
\hline Cassia siamea Lam. & cassia-amarela & exótica & $1,2,3,4$ \\
\hline Delonix regia (Bojer ex Hook.) Raf. & flamboyant & exótica & $2,3,4$ \\
\hline Erythrina speciosa Andrews & mulungu & exótica & 2 \\
\hline Leucaena leucocephalla (Lam.) de Wit. & leucena & exótica & 4 \\
\hline Pterogyne nitens Tul. & amendoim-bravo & nativa & 4 \\
\hline Indet 2 & - & - & 3 \\
\hline \multicolumn{4}{|l|}{ MALVACEAE } \\
\hline Chorisia speciosa A. St.-Hil. & paineira & nativa & 1,2 \\
\hline Pachira aquatica Aubl. & munguba & nativa & $1,3,4$ \\
\hline \multicolumn{4}{|l|}{ MELIACEAE } \\
\hline Guarea guidonia (L.) Sleumer & carrapeta & nativa & 1 \\
\hline \multicolumn{4}{|l|}{ MORACEAE } \\
\hline Ficus benjamina L. & ficus-benjamim & exótica & 1,4 \\
\hline Ficus religiosa $\mathrm{L}$. & figueira-da-índia & exótica & 3,4 \\
\hline \multicolumn{4}{|l|}{ MYRTACEAE } \\
\hline Psidium guajava L. & goiaba & nativa & 4 \\
\hline Syzygium cumini L. (Skeels) & jamelão & exótica & 3 \\
\hline \multicolumn{4}{|l|}{ PANDANACEAE } \\
\hline Pandanus utilis Bory & - & exótica & 4 \\
\hline \multicolumn{4}{|l|}{ SAPINDACEAE } \\
\hline Sapindus saponaria L. & sabão-de-soldado & nativa & 4 \\
\hline \multicolumn{4}{|l|}{ STERCULIACEAE } \\
\hline Sterculia foetida L. & chichá fedorento & exótica & 4 \\
\hline \multicolumn{4}{|l|}{ STRELITZIACEAE } \\
\hline Ravenala madagascariensis Sonn. & árvore-do-viajante & exótica & 4 \\
\hline \multicolumn{4}{|l|}{ INDETERMINADA } \\
\hline Indet 3 & - & - & 2 \\
\hline
\end{tabular}

Praças: 1 - Castilho França; 2 - Varnhagen; 3 - Saens Pena; 4 - Xavier de Brito. 
todas as espécies amostradas, dentre elas estão: Pandanus utilis, Erythrina speciosa, Handroanthus heptaphyllus, Mangifera indica, Chorisia speciosa, Ficus benjamina, Cassia fistula, Chamaerops humilis, Cocos nucifera, Leucaena leucocephalla, Pterogyne nitens, Alchornea triplinervia, Caesalpinia pulcherrima, Psidium guajava, Sapindus saponaria, Schinus terebinthifolius, Sterculia foetida, Syzygium cumini, Tamarindus indica, Guarea guidonia, entre outras. Silva et al., (2007) encontraram 41 espécies que foram consideradas raras representando $47 \%$ das espécies encontradas nos parques recifenses.

Do total de espécies encontradas nas quatro praças, foi possível observar pouca diferença em relação às espécies nativas e exóticas, 57,2\% e 42,8\%, respectivamente. Por outro lado, no bairro da Taquara, segundo Souza \& Cintra (2007), foi observado ligeiro predomínio das espécies exóticas (53\%) sobre as de origem nativa (47\%).

Com relação ao número de indivíduos encontrados nas quatro praças, as espécies exóticas representaram a maioria absoluta, com pouco mais de $90 \%$ do número total de indivíduos. Teixeira (1999), ao analisar a arborização do Conjunto Residencial Tancredo Neves, RS, afirma ter encontrado uma situação semelhante, na qual $44 \%$ dos indivíduos eram de origem nativa e $56 \%$ de origem exótica.

Lindenmaier \& Santos (2008), ao avaliarem as áreas verdes e praças em Cachoeira do Sul, RS, encontraram valor semelhante a esse estudo: as espécies exóticas eram responsáveis por $58 \%$ do total das espécies utilizadas na arborização urbana.

$\mathrm{Na}$ totalidade das praças avaliadas, as espécies consideradas nativas são representadas, principalmente, por: Caesalpinia ferrea (28 indivíduos), C. peltophoroides (28 indivíduos), C. echinata (18 indivíduos), Licania tomentosa (17 indivíduos), Syagrus romanzoffiana (10 indivíduos), Tabebuia rosea (9 indivíduos) e Pachira aquatica (8 indivíduos).

No conjunto das praças, a avaliação do porte dos indivíduos demonstrou que $15,1 \%$ dos exemplares apresentaram altura inferior a $5 \mathrm{~m}, 41,5 \%$ dos indivíduos apresentaram altura de $5 \mathrm{~m}$ a $10 \mathrm{~m}, 42,1 \%$, altura entre $10 \mathrm{~m}$ e $15 \mathrm{~m}$ e apenas $1,3 \%$ apresentaram altura superior a $15 \mathrm{~m}$ (Figura 2).

O porte dos exemplares encontrados nas quatro praças demonstra que a arborização é composta por árvores em sua grande maioria de idade já avançada, representadas na Figura 2, o que corrobora trabalho de Redin et al. (2010), realizado em cinco praças situadas no município de Cachoeira do Sul, RS).

Conforme a Figura 2, pode-se observar que a praça que recebeu maior incremento de indivíduos jovens foi a Castilho de França: dentre os 27 replantados recentemente, mais de $30 \%$ pertencem às espécies Caesalpinia echinata e C. peltophoroides, totalizando 12 indivíduos. Não obstante, as demais praças não

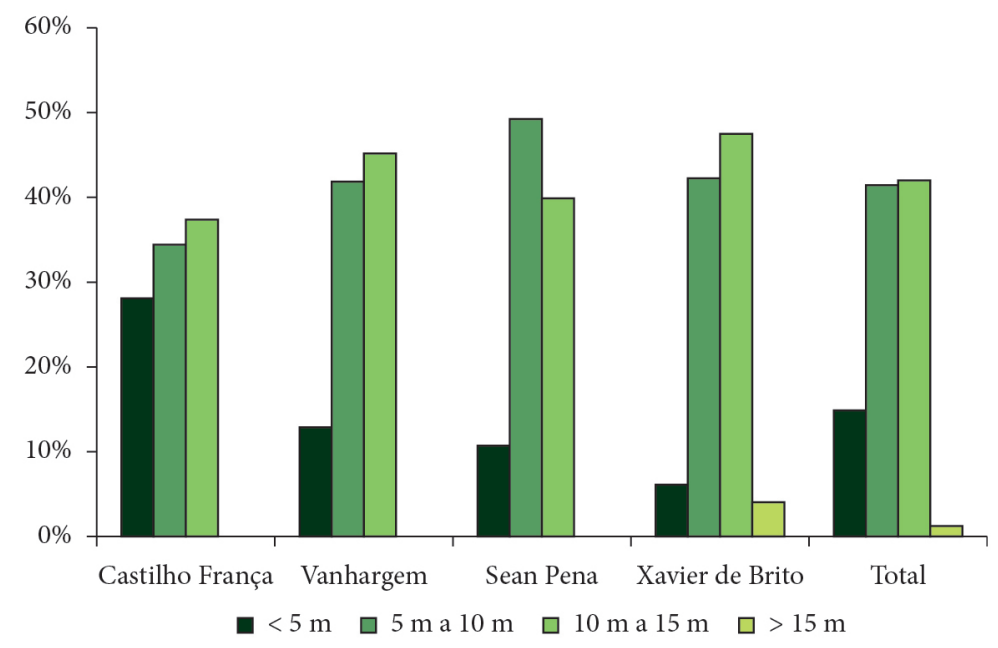

Figura 2. Distribuição da frequência dos intervalos de altura dos indivíduos presentes em quatro praças no bairro da Tijuca, Rio de Janeiro, RJ, Brasil.

Figure 2. Frequency distribution of heigth classes of trees in four squares in Tijuca, Rio de Janeiro, Brazil. 
seguiram o mesmo padrão, suas árvores estão decrépitas, senis, e as que oferecem risco à integridade física dos usuários deveriam ser paulatinamente substituídas por indivíduos jovens, sempre que possível por espécies autóctones.

Quanto aos resultados obtidos com as medições de DAP (diâmetro à altura do peito), foi possível observar que cerca de 50\% dos indivíduos apresentaram DAP superior a $30 \mathrm{~cm}$, os quais são a maioria absoluta dos indivíduos. Por outro lado, apenas $26,8 \%$ das árvores apresentaram diâmetros até $15 \mathrm{~cm}$. Esses dados corroboram com o fato de que, com exceção da Praça Castilho França, não vêm sendo praticadas ações de manejo visando a substituição dos indivíduos caducos, conforme exposto acima.

Quando comparados com a distribuição das frequências dos diâmetros (DAP), fica evidente a maior participação de árvores maduras em detrimento das jovens, demonstrando baixa renovação dos elementos arbóreos das praças analisadas (Figura 3).

Quanto à avaliação da fitossanidade, do total dos indivíduos presentes nas quatro praças da Tijuca foi possível diagnosticar que $64,5 \%$ estavam saudáveis, demonstrando boas condições de raízes e parte aérea, $25,4 \%$ apresentaram sintomas comuns de ataques de pragas e organismos patogênicos, como machas nas folhas, perfurações no tronco e raízes, queda prematura das folhas e parte aérea visivelmente danificada; 10,1\% sofreram injúrias mecânicas de vários tipos, como cortes nos troncos, por objetos aderidos de forma inadequada, como pregos, correntes, ataque bem avançado de organismos patogênicos no tronco, criando ocos e podridões do caule (Figura 4). O mesmo padrão foi observado por Redin et al. (2010) ao analisarem o estado fitossanitário das árvores presentes em cinco praças situadas no município de Cachoeira do Sul, RS.

A educação ambiental pode servir como um importante instrumento na gestão e conservação da arborização urbana. As ações de educação ambiental consolidadas pela Agência Municipal de Meio Ambiente (AMMA) de Goiânia vêm alcançando ótimos resultados na sensibilização da população sobre a qualidade ambiental da cidade, como no caso da arborização urbana. Segundo Dourado (2010), Goiânia passou a ser uma referência nacional em termos de arborização, com mais de 900 mil arvores plantadas em áreas públicas na cidade, superando Curitiba (300 mil) e João Pessoa (40 mil), contando com amplo engajamento da população, desde nas atividades de plantio voluntário até o apoio a fiscalização através de denúncias.

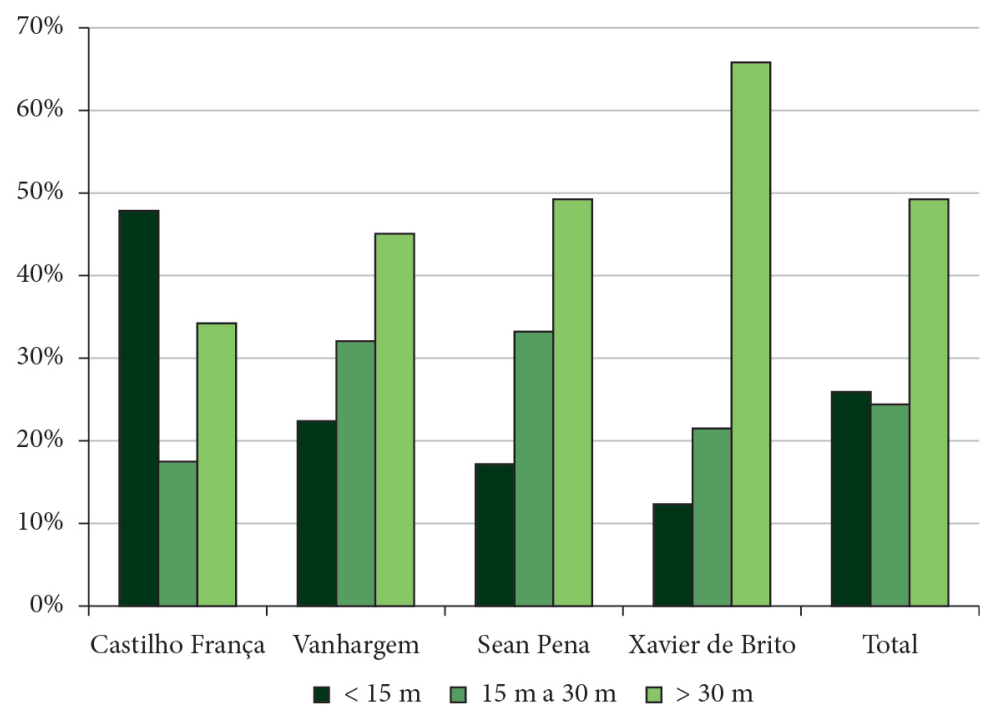

Figura 3. Distribuição da frequência dos intervalos de diâmetro a altura do peito (DAP) dos indivíduos presentes em quatro praças no bairro da Tijuca, Rio de Janeiro, RJ, Brasil.

Figure 3. Frequency distribution of Diameter of Breast Height (DBH) of trees in four squares in Tijuca, Rio de Janeiro, Brazil. 


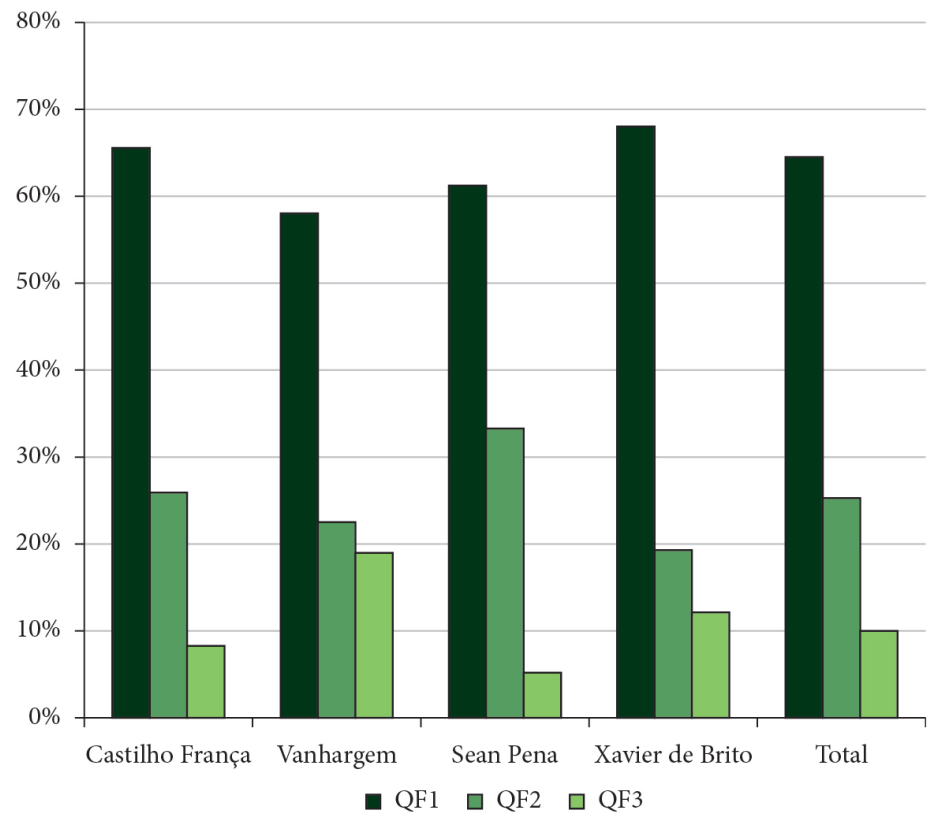

Figura 4. Distribuição da frequência dos intervalos de qualidade de fuste (QF) dos indivíduos presentes em quatro praças no bairro da Tijuca, Rio de Janeiro, RJ, Brasil.

Figure 4. Frequency distribution of Stem Quality (SQ) of trees in four squares in Tijuca, Rio de Janeiro, Brazil.

\section{CONCLUSÕES}

Nas quatro praças analisadas no bairro da Tijuca, Rio de Janeiro, RJ, foram encontrados ao todo 310 indivíduos, distribuídos em 36 espécies, 30 gêneros e 14 famílias botânicas.

Apesar da presença de muitas espécies, pôde-se constatar através deste estudo a existência de uma relativa uniformidade na arborização nos locais estudados, já que as espécies Cassia siamea e Delonix regia, juntas, totalizaram $32,4 \%$ do total de indivíduos encontrados nas quatro praças.

É possível concluir através desse fato que a maioria dos indivíduos encontrados nas quatro praças do bairro possuía grande porte e/ou já se encontrava em idade avançada. Recomenda-se a substituição dos indivíduos caducos por árvores novas, adotando-se o maior número de espécies possíveis, preferencialmente nativas, para evitar a uniformidade.

\section{STATUS DA SUBMISSÃO}

Recebido: 17 dez., 2012

Aceito: 10 set., 2014

\section{AUTOR(ES) PARA CORRESPONDÊNCIA}

\section{Welington Kiffer de Freitas}

Escola de Engenharia Industrial e Metalúrgica - EEIMVR, Universidade Federal Fluminense UFF, Volta Redonda, RJ, Brasil

e-mail: wkfreitas@gmail.com

\section{REFERENNCIAS}

Albertin RM, De Angelis F, De Angelis Neto R, De Angelis BLD. Diagnóstico quali-quantitativo da arborização viária de Nova Esperança, Paraná, Brasil. Revista da Sociedade Brasileira de Arborização Urbana 2011; 6(3): 128-148.

Angiosperm Phylogeny Group - APG III. An update of the Angiosperm Phylogeny Group classification for the orders and families of flowering plants: APG III. Botanical Journal of the Linnean Society 2009; 161(2): 105-121. http:// dx.doi.org/10.1111/j.1095-8339.2009.00996.x.

Braga L, Flemming L. Uma Análise das Praças Públicas da Tijuca: perspectiva do usuário. Revista Ciência e Tecnologia 2010; 1(1): 10-23.

Dourado R. Goiânia: a capital mais verde do Brasil. Revista ecoLÓGICA 2010. [cited 2012 May 14]. Available from: http:// http://www.revistaecologica.com/edicoes/5a-edicao/.

Forzza RC, Leitman PM, Costa AF, Carvalho AA, Peixoto AL, Walter BMT, et al. Introdução. Lista de Espécies da 
Flora do Brasil. Rio de Janeiro: Jardim Botânico do Rio de Janeiro; 2010. [cited 2012 May 10]. Available from: http://floradobrasil.jbrj.gov.br/2010/.

Freitas SR, Neves CL, Chernicharo P. Tijuca National Park: two pioneering restorationist initiatives in Atlantic forest in southeastern Brazil. Brazilian Journal of Biology 2006; 66(4): 975-982. http://dx.doi.org/10.1590/S151969842006000600004. PMid:17299933

Gonçalves W, Paiva HN. Árvores para ambiente urbano. Viçosa: Editora UFV; 2004. 242 p. Coleção Jardinagem e Paisagismo n. 2.

Harder ICF, Ribeiro RCS, Tavares AR. Índices de área verde e cobertura vegetal para as praças do Município de Vinhedo, SP. Revista Árvore 2006; 30(2): 277-282. http:// dx.doi.org/10.1590/S0100-67622006000200015.

Harder, ICF. Inventario quali-quantitativo da arborização e infra estrutura das Praças da cidade de Vinhedo/SP [dissertação]. Piracicaba: Escola Superior de Agricultura Luiz de Queiroz, Universidade de São Paulo; 2002.

Instituto de Pesquisa Econômica Aplicada - IPEA. Índice de Desenvolvimento Humano - IDH. Rio de Janeiro; 2000. [cited 2012 May 5]. Available from: http://www. ipeadata.gov.br.

Instituto Pereira Passos - IPP. Armazém de Dados / Bairros Cariocas. Rio de Janeiro; 2012. [cited 2012 May 10]. Available from: http://portalgeo.rio.rj.gov.br/ bairroscariocas.

Kramer JA, Krupek RA. Caracterização florística e ecológica da arborização de praças públicas do município de Guarapuava, PR. Revista Árvore 2012; 36(4): 647-658. http://dx.doi.org/10.1590/S0100-67622012000400007.

Lindenmaier DS, Santos NO. Arborização urbana das praças de Cachoeira do Sul RS-Brasil: fitogeografia, diversidade e Índice de áreas verdes. São Leopoldo: Instituto Anchietano de Pesquisas; 2008. p. 307-320. Pesquisas, Série Botânica n. 59.

Mendonça EMS. Apropriações do espaço público: alguns conceitos. Revista Estudos e Pesquisas em Psicologia 2007; 7(2): 122-132.

Missouri Botanical Garden - MOBOT. Explore the beta release of Web TROPICOS. citation on computers documents. [cited 2012 Sept. 3]. Available from: http:// mobot.mobot.org/W3T.
Nucci JC. Qualidade ambiental e adensamento: um estudo de planejamento paisagem de Santa Cecília (MSP) [tese]. São Paulo: Departamento de Geociências, Faculdade de Filosofia, Letras e Ciências Humanas, Universidade de São Paulo; 1996.

Redin CG, Vogel C, Trojahn CDP, Gracioli CR, Longhi SJ. Análise da arborização urbana em cinco praças do município de Cachoeira do Sul, RS. Revista da Sociedade Brasileira de Arborização Urbana 2010; 5(3): 149-164.

Rocha RT, Leles PSS, Oliveira Neto SN. Arborização de vias públicas em Nova Iguaçu, RJ: o caso dos bairros Rancho Novo e Centro. Revista Árvore 2004; 28(4): 599-610. http:// dx.doi.org/10.1590/S0100-67622004000400014.

Romani GN, Gimenes R, Silva MT, Pivetta KFL, Batista GS. Análise quali-quantitativa da arborização na praça XV de novembro em Ribeirão Preto - SP, Brasil. Revista Árvore 2012; 36(3): 479-487. http://dx.doi.org/10.1590/ S0100-67622012000300010.

Secretaria Municipal de Meio Ambiente - SMAC. História do Rio. 2012b. [cited 2012 June 18]. Available from: http:// www.rio.rj.gov.br/web/smac/exibeconteudo?articleid $=87129 /$.

Secretaria Municipal de Meio Ambiente - SMAC. Mapeamento da cobertura vegetal e do uso das terras do município do Rio de Janeiro. 2012a. [cited 2012 May 14]. Available from: http://www.rio.rj.gov.br/web/smac/.

Silva Filho DF, Bortoleto S. Uso de indicadores de diversidade na definição de plano de manejo da arborização viária de Águas de São Pedro SP. Revista Árvore 2005; 29(6): 973 982. http://dx.doi.org/10.1590/S0100-67622005000600017.

Silva LR, Meunier IMJ, Miranda AMF. Riqueza e densidade de árvores, arvoretas e palmeiras em parques urbanos de Recife, Pernambuco, Brasil. Revista da Sociedade Brasileira de Arborização Urbana 2007; 2(4): 34-49.

Souza AL, Ferreira RA, Mello AA, Plácido DR, Santos CZA, Graça DAS, et al. Diagnóstico quantitativo e qualitativo da arborização das praças de Aracaju, SE. Revista Árvore 2011; 35(6): 1253-1263. http://dx.doi.org/10.1590/S010067622011000700012

Souza RC, Cintra DP. Arborização viária e conflitos com equipamentos urbanos no bairro da Taquara, RJ. Revista Floresta e Ambiente 2007; 14(1): 25-33.

Teixeira IF. Análise qualitativa da arborização de ruas do conjunto habitacional Tancredo Neves, Santa Maria - RS. Revista Ciência Florestal 1999; 9(2): 9-21. 